\title{
Androgen aromatization by luteinized bovine granulosa cells in tissue culture
}

\author{
K. M. Henderson and I. A. Swanston \\ M.R.C. Reproductive Biology Unit, Clinical Laboratory, \\ Simpson Memorial Maternity Pavilion, Royal Infirmary, Edinburgh, EH3 9EF, U.K.
}

\begin{abstract}
Summary. Luteinized bovine granulosa cells in tissue culture contained an active 19-hydroxylase aromatase enzyme system which converted exogenous androstenedione and testosterone to oestradiol-17 $\beta$; no oestrone was detected. In the absence of exogenous androgens, the cells failed to synthesize oestrogens due to a limited capacity to synthesize androgen precursor. Theca-lutein cells, present in those CL which synthesize oestrogens, may provide androgen precursor for aromatization by the granulosa-lutein cells.
\end{abstract}

From studies involving short-term incubations with ${ }^{14} \mathrm{C}$-labelled radioactive precursors, Savard $\&$ Telegdy (1965) concluded that the bovine corpus luteum could not synthesize oestrogens because it lacked the 17-hydroxylase, 17,20-lyase and 19-hydroxylase aromatase enzyme systems necessary for androgen synthesis and aromatization. By using a sensitive, specific radioimmunoassay for testosterone, Shemesh, Hansel \& Concannon (1975) observed that the bovine corpus luteum did have the enzymic capacity to synthesize small amounts of testosterone. However, these authors did not reexamine the capacity of the bovine corpus luteum to aromatize androgens to oestrogen. Bovine granulosa cells obtained from Graafian follicles and induced to luteinize in tissue culture provide a convenient system in which to study the bovine corpus luteum which is composed mainly of granulosalutein cells (Gier \& Marion, 1961). We have used this system to study the relative production of progesterone, androgens and oestrogens.

\section{Materials and Methods}

Bovine granulosa cells, harvested and pooled from antral follicles, were cultured as described previously (McNatty \& Sawers, 1975). Briefly, a minimum of $1.5 \times 10^{5}$ 'live' cells were cultured in 1 $\mathrm{ml}$ culture medium consisting of $20 \%$ calf serum and $80 \%$ Medium 199 containing HEPES buffer and supplemented with glutamine and antibiotics. Exogenous androstenedione (1-500 ng) or testosterone (1-500 ng) was added daily throughout the culture period in $10 \mu$ l ethanol. Control cultures received $10 \mu \mathrm{l}$ ethanol only. The culture medium was replaced daily and stored at $-20^{\circ} \mathrm{C}$ until radioimmunoassay of steroids. At the end of the culture period, the cells were stained with haematoxylin and eosin and counted by means of a haemocytometer. Luteinization of the granulosa cells was indicated by a sustained production of progesterone, accompanied by cellular hyperplasia and hypertrophy with an increase in the cytoplasmic-nuclear ratio.

The progesterone content of the culture medium was assayed directly by the method previously validated by Neal, Baker, McNatty \& Scaramuzzi (1975). Oestradiol-17 $\beta$, oestrone, androstenedione and testosterone were extracted from the culture medium and measured by specific radioimmunoassays as described previously for plasma, except that the chromatographic steps were omitted because they were found to be unnecessary (Rowe, Cook \& Dean, 1973; Baird, Burger, Heavon-Jones \& Scaramuzzi, 1974; Corker \& Davidson, 1978; Van Look, Hunter, Corker \& Baird, 1977). The intra- and inter-assay coefficients of variation of all the assays, calculated by the method of Snedecor (1952), were each $<10 \%$ and $<16 \%$ respectively. The limit of sensitivity of the assays was $50 \mathrm{pg}$ for progesterone, $5 \mathrm{pg}$ for oestrone and oestradiol and $10 \mathrm{pg}$ for the two androgens. Control cultures containing added amounts of androstenedione (1-500 ng) or testosterone (1-500 ng), but no cells, allowed corrections to be made for any cross-reaction of the exogenous androstenedione or testosterone with the different antisera. 


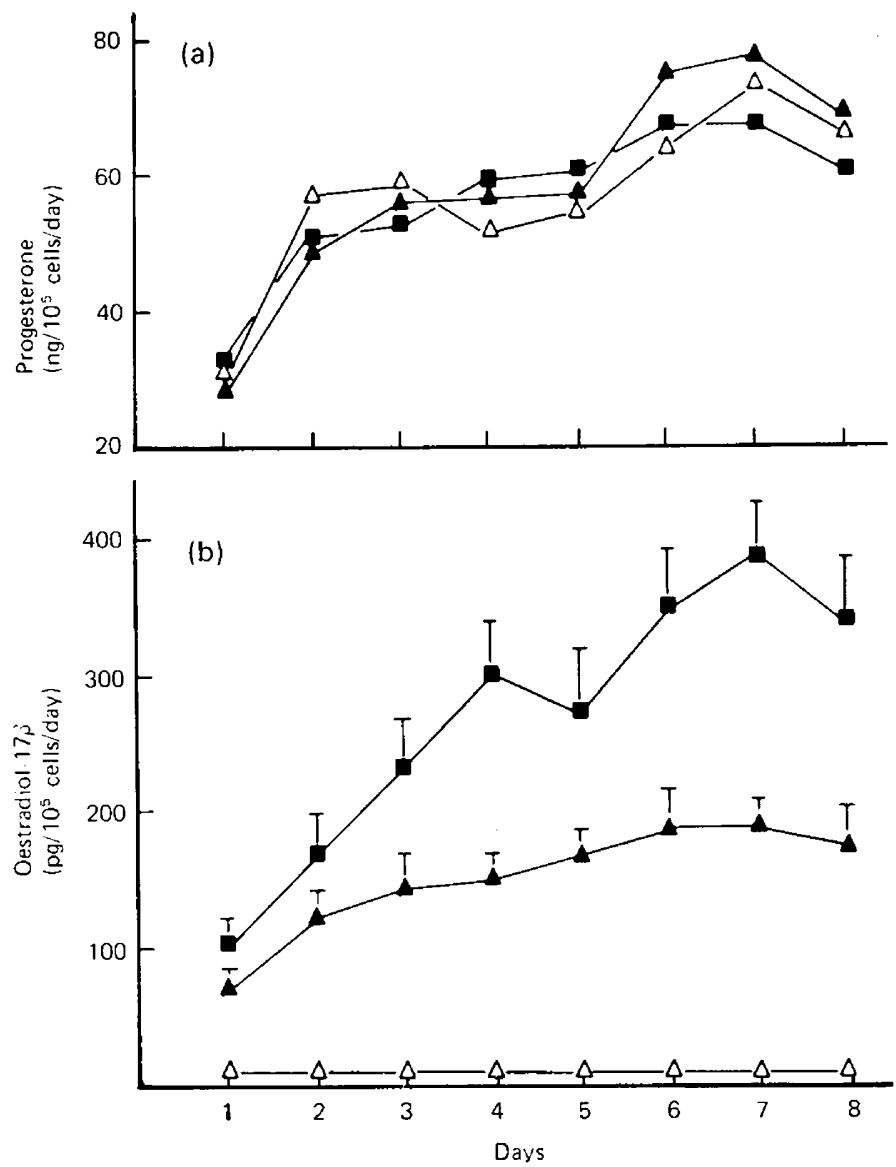

Text-fig. 1. Daily production of (a) progesterone and (b) oestradiol-17 $\beta$ by luteinized bovine granulosa cells in tissue culture. Each point is the mean of 8 replicate cultures: the s.d. lines have been omitted in (a) for clarity, but no significant differences between the groups were observed $(P>0.05$, paired $t$ test). $\triangle$, Control; $\mathrm{E}, 100 \mathrm{ng}$ testosterone/day; $\Delta, 100 \mathrm{ng}$ androstenedione/day.

\section{Results and Discussion}

Text-figures 1(a) and 1(b) show the progesterone and oestradiol-17 $\beta$ production by control cultures and those to which testosterone or androstenedione had been added. In addition to progesterone, the control cultures produced small amounts of androstenedione and testosterone (20-50 pg/10 day) but no oestrogens. Steroid secretion by the cultures could not be increased further by the daily addition of NIH ovine gonadotrophins (100 ng each of LH and FSH). This indicates that the endogenous gonadotrophins present in the culture medium (50 ng FSH/ml, $3 \mathrm{ng} \mathrm{LH} / \mathrm{ml}$ and $9 \mathrm{ng}$ prolactin/ml, as determined by specific radioimmunoassays for ovine gonadotrophins) and originating from the added calf serum were sufficient to cause full functional luteinization of the granulosa cells. The small amounts of androstenedione and testosterone secreted by the control cultures together with progesterone supports the finding of Shemesh et al. (1975) that the bovine corpus luteum is not entirely devoid of 17-hydroxylase and 17,20-lyase enzymes. Oestradiol-17 $\beta$ was produced only when exogenous androstenedione or testosterone was added to the cultures, a daily dose of $100 \mathrm{ng}$ resulting in maximum production. Significantly more oestradiol-17 $\beta$ was, however, produced in response to testosterone than to androstenedione $(P<0.01$, paired $t$ test $)$, a finding consistent with those of Oakey \& Stitch (1967) who studied slices of rat ovary. This, and the fact that none of the control or androgen-treated cultures produced detectable amounts of oestrone, suggests that oestradiol $17 \%$ 
is synthesized by conversion of testosterone rather than oestrone. Progesterone production by the luteinized cells was unaffected by the daily addition of either androgen up to the maximum amount tested of $500 \mathrm{ng} /$ culture/day. The cellular capacity to synthesize progesterone was approximately 200fold greater than its ability to aromatize androgens. This may be attributable, at least in part, to the presence of very much more mitochondrial than microsomal cytochrome P-450 in luteinized granulosa cells as in the bovine corpus luteum (McIntosh, Uzgiris, Alonso \& Salhanick, 1971). Mitochondrial cytochrome P-450 is required for progesterone biosynthesis while microsomal cytochrome P-450 is required for androgen aromatization (Savard, 1973).

Our findings indicate that luteinized bovine granulosa cells, although having an active 19-hydroxylase aromatase system, do not synthesize oestradiol-17 $\beta$ because of their limited capacity to synthesize androgens. Oestradiol-17 $\beta$ production by a corpus luteum may therefore require a positive cooperative interaction between granulosa-lutein and theca-lutein cells similar to that suggested for oestradiol-17 $\beta$ production by the follicle (see Moor, 1977, for references). In human (Hammerstein, Rice \& Savard, 1964) and pig (Watson \& Leask, 1975) corpora lutea, which do synthesize oestradiol$17 \beta$, granulosa-lutein and theca-lutein cells are easily distinguishable (Corner, 1919; Guraya, 1971). The theca-lutein cells might therefore provide androgen precursor for aromatization to oestradiol$17 \beta$ by the granulosa-lutein cells. There are few distinguishable theca-lutein cells in the cow (Gier \& Marion, 1961) and ewe (Harrison, 1948) corpus luteum and therefore oestradiol-17ß may not be synthesized because the granulosa-lutein cells receive an inadequate supply of androgen precursor.

We are grateful to Dr A. S. McNeilly for measuring the gonadotrophin content of the culture medium, and to Rhona Cunningham for her assistance with some of the testosterone assays. K.M.H. acknowledges the financial support of the Medical Research Council.

\section{References}

Baird, D.T., Burger, P.E., Heavon-Jones, G.D. \& ScaramuzzI, R.J. (1974) The site of secretion of androstenedione in non-pregnant women. J. Endocr. 63, 201-212.

CoRker, C. \& DAVIDSON, D. (1978) The radioimmunoassay of testosterone in various biological fluids without chromatography. J. Steroid Biochem. (in press).

CORNER, G.W. (1919) On the origin of the corpus luteum of the sow from both granulosa and theca interna. Am. J. Anat. 26, 117-183.

Gier, H.T. \& MARION, G.B. (1961) Formation of the bovine corpus luteum. J. Dairy Sci. 44, 1187-1192.

Guraya, S.S. (1971) Morphology, histochemistry and biochemistry of human ovarian compartments and steroid hormone biosynthesis. Physiol. Rev. 51, 785807.

Hammerstein, J., Rice, B.F. \& SAVARd, K. (1964) Steroid formation in the human ovary. I. Identification of steroids formed in vitro from ${ }^{14} \mathrm{C}$-acetate in the corpus luteum. J. clin. Endocr. Metab. 24, 597-605.

Harrison, R.J. (1948) The development and fate of the corpus luteum in the vertebrate series. Biol. Rev. 23, 296-331.

McIntosh, E.N., Uzgiris, V.I., Alonso, C. \& SalHANICK, H.A. (1971) Spectral properties, respiratory activity and enzyme systems of bovine corpus luteum mitochondria. Biochemistry, N.Y. 10, 29092916.
MCNATTY, K.P. \& SAWERS, R.S. (1975) The relationship between the endocrine environment within the Graafian follicle and the subsequent rate of progesterone secretion by human granulosa cells in vitro. J. Endocr. 66, 391-400.

MoOR, R.M. (1977) Sites of steroid production in ovine Graafian follicles in culture. $J$. Endocr. 73, 143-150.

Neal, P., Baker, T.G., MCNatTy, K.P. \& Scaramuzzi, R.J. (1975) Influence of prostaglandins and human chorionic gonadotrophin on progesterone concentrations and oocyte maturation in mouse ovarian follicles maintained in organ culture. $J$. Endocr. 65, 19-25.

OAKEY, R.E. \& Stitch, S.R. (1967) Oestrogen synthesis in vitro by ovaries from rats in different phases of the oestrous cycle. J. Endocr. 39, 189-195.

Rowe, P.H., COOK, I.F. \& DEAN, P.D.G. (1973) Oestrone specific antisera raised against oestrone-6(O-carboxymethyl) oxime-bovine serum albumin. Steroids Lipids Res. 4, 24-29.

SAVARD, K. (1973) The biochemistry of the corpus luteum. Biol. Reprod. 8, 183-202.

SaVARD, K. \& TElegdy, G. (1965) Steroid formation in the bovine corpus luteum. Steroids 5, Suppl. II, 205-210.

Shemesh, M., Hansel, W. \& Concannon, P.W. (1975) Testosterone synthesis in the bovine corpus luteum. Biol. Reprod. 13, 490-493.

SNEDECOR, G.W. (1952) Queries. Biometrics 8, 85-86.

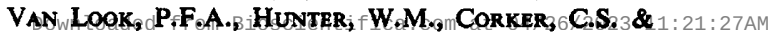


BAIRD, D.T. (1977) Failure of positive fedback in normal men and subjects with testicular feminization. Clin. Endocr. (in press).
WATzON, J. \& Lack, JiT.S. (1975) Superfusion in vitro in the study of ovarian steroidopenesis. J. Endocr. 64, 163-173.

Recelved 39 Ming 1877 